\title{
As práticas da Psicologia nas políticas públicas de assistência social, segurança pública e juventude
}

\author{
The psychological practices in public policies of social assistance, pu- \\ blic secutity and youth
}

http://dx.doi.org/10.5007/2178-4582.2015v49n2p60

\author{
Andréa Cristina Coelho Scisleski \\ Universidade Católica Dom Bosco, Campo Grande/MS, Brasil \\ Hebe Signorini Gonçalves \\ Universidade Federal do Rio de Janeiro, Rio de Janeiro/RJ, Brasil \\ Lilian Rodrigues da Cruz \\ Universidade Federal do Rio Grande do Sul, Porto Alegre/RS, Brasil
}

\begin{abstract}
A partir da implementação do Sistema Único da Assistência Social (SUAS) no Brasil tem crescido o número de psicólogos nos serviços de assistência social, segurança e juventude. Neste sentido, a assistência social, articulada a outras políticas públicas de proteção social voltada à garantia de direitos, constitui-se como lócus de investigação e problematização no campo da Psicologia. Assim, o artigo propõe-se analisar o lugar da Psicologia nas políticas públicas de assistência, segurança e juventude, primeiramente a partir da herança positivista da Psicologia e, em um segundo momento, enfoca as práticas e leva em conta que as políticas públicas implementam os direitos constitucionais, mas os processos que as operacionalizam e os obstáculos que elas enfrentam abrem estratégias de intervenção variadas. Para fomentar o debate sugerimos permanente problematização de pelo menos três questões: o que estamos fazendo; como estamos fazendo e quais os efeitos dessas práticas.

Palavras-chave: Práticas psicológicas. Assistência social. Segurança pública. Juventude. Políticas públicas.
\end{abstract}

From the implementation of the Public Social Assistance System, in Brazil, the number of psychologists has increased in social, security and youth services. In this sense, social assistance coordinated with other public policies of social protection directed to guarantee rights that has constituted as a place of research and problematization in the psychological field. Thus, this article aims to analyze the place of psychology in public policies of assistance, security and youth in two directions: first, from the positivist heritage of psychology; and, in a second way, it focuses on the practices taking into account how public policies implement the constitutional rights, but the processes that operationalize and the obstacles they face open several intervention strategies. To foster this debate, we suggest a permanent problematization of, at least, three questions: what are we doing, as are we doing and what are the effects of these practices.

Keywords: Psychological practice. Social assistance. Public security. Youth. Public policy.

\section{Introdução}

Reza a Constituição Federal que a assistência social é direito do cidadão e dever do Estado. O Sistema Único de Assistência Social (SUAS), instituído em 2005 e regulado pela Lei 12.435/2011, unifica as ações da Assistência Social a nível nacional, ratificando seu caráter de política pública de garantia de direitos. O novo modelo de gestão da assistência prioriza a família como 
foco de atenção e o território como base da organização de ações e serviços em dois níveis de atenção: proteção social básica e proteção social especial. O primeiro destina-se à população que vive em situação de vulnerabilidade social decorrente da pobreza, com precário acesso aos serviços públicos e/ ou fragilização de vínculos afetivos. Esse conjunto de ações é desenvolvido no Centro de Referência em Assistência Social (CRAS), visa as famílias em situação de vulnerabilidade social e tem como perspectiva o fortalecimento de vínculos familiares e comunitários. A Proteção Social Especial, desenvolvida nos Centros de Referência Especializados em Assistência Social (CREAS), caracteriza-se como a modalidade de atendimento destinada a famílias e indivíduos em situação de risco pessoal e social, por violação de direitos ou contingências que demandem intervenção especializada; incluem-se aí os maus tratos e violências, o trabalho infantil e o cumprimento de medidas socioeducativas (este último regulado pela Resolução CNAS 18/2014).

A implementação desses Centros tem crescido significativamente nos últimos anos, o que amplia o número de psicólogos atuando no território das políticas de assistência, já que o SUAS estabelece a inclusão do profissional da Psicologia na equipe mínima tanto do CRAS como do CREAS. Neste sentido, a assistência social, articulada a outras políticas públicas de proteção social voltada à garantia de direitos e condições dignas de vida, constitui-se como lócus de investigação e problematização no campo da Psicologia. A produção recente tem enfatizado, de fato, a urgência de reformulação do paradigma psicológico nesse campo. Muitos pesquisadores apontam a necessidade e a conveniência de abandonar a psicologização, entendida como o recurso a explicações que reduzem o entendimento do sujeito ao plano individual e subjetivo, argumentando que essa linha de análise e intervenção oculta as diversas formas de dominação e controle que espreitam as políticas assistenciais, esvaziando politicamente a ação do psicólogo no campo.

Este artigo dialoga com essa produção e examina o lugar da Psicologia nas políticas públicas de assistência, segurança e juventude a partir de dois eixos principais. O primeiro diz respeito à herança positivista da Psicologia. Historicamente, a tônica da intervenção psicológica tem sido a adequação das pessoas à norma: a Psicologia, e os psicólogos, autorizam-se a estabelecer critérios de normalidade e anormalidade a partir dos quais sujeitos são classificados como aptos ou inaptos, corrigíveis ou incorrigíveis, construindo dispositivos de controle que os submetem a modos de vida predeterminados. O segundo eixo enfoca as práticas e leva em conta que as políticas públicas implementam os direitos constitucionais, mas os processos que as operacionalizam e os obstáculos que elas enfrentam abrem estratégias de intervenção variadas, submetendo-as ao entendimento particular de cada gestão. Em conjunto, esses eixos 
produzem efeitos sobre os modos de ser sujeito na atualidade: adolescente em conflito com a lei, beneficiário de bolsa família, criança abrigada, oficineiro do CRAS e - também - psicólogo que atua no CREAS.

\section{Políticas públicas e estratégias de governo}

Se seguirmos os rastros de Foucault, diremos que a Psicologia alçou o status de ciência prestando serviços às demais: à educação, à medicina, ao direito... Ela se constituiu assim como uma ciência utilitarista, que recorre a técnicas e métodos para atender, sem problematizar, as demandas a ela endereçadas.

No Brasil, o psicólogo se inseriu no campo da assistência antes desta se constituir como política pública, e antes mesmo do reconhecimento da Psicologia como profissão. Entre ensaios de aproximação de campos ainda em formação, a psicologia configurou modos de ação que respondiam à lógica utilitarista e de controle. Em particular no que diz respeito à infância pobre, desde os anos 1930 o psicólogo auxiliava o Juízo de Menores nas funções de abrigar e distribuir crianças que necessitavam de proteção e assistência, valendo-se de instrumentos que queriam determinar as causas do "desvio do menor". O exame psicológico procurava investigar o nível intelectual da criança e a existência de distúrbios psíquicos: a investigação era realizada mediante o uso de testes e visava classificar, para resgatar o "desviante" e enquadrá-lo à norma. O pensamento psicológico legitimou a exclusão e a desqualificação de crianças e jovens pobres, pois estava centrado no indivíduo, desconsiderando os aspectos sociais que compunham seu dito "desvio" (OLIVEIRA, 2001). Desde então, e sob os auspícios da psicologia nascente, vem se formando uma visão segundo a qual a questão social seria produto de ações e escolhas individuais, razão pela qual sua solução igualmente poderia ser encontrada no indivíduo.

Na obra em que se propõe a analisar a reconfiguração da questão social na sociedade contemporânea, Castel (1999) afirma que ela se desenha a partir de três vertentes: a desestabilização dos trabalhadores estáveis; sua instalação na precariedade; e a constituição de uma população sobrante. Sua análise mostra que aquilo que nomeamos como questão social resulta da conjugação de problemas políticos, sociais e econômicos cujos efeitos são detectáveis a nível dos sujeitos: a pobreza, a miséria ou a violência... Ainda que não se proponha a tematizar mais diretamente a questão do sujeito, o autor indica que hoje ele se produz no interior de uma racionalidade liberal que ativamente o faz vulnerável. Essa vulnerabilidade, segundo Castel (1999), atinge sobretudo os jovens e exige políticas sociais renovadas. 
Resta-nos assim, a nós psicólogos, debruçarmo-nos sobre a repercussão da nova questão social sobre os sujeitos, para entendê-los e para operar com eles. No caso brasileiro, esse desafio enfrenta uma história da psicologia junto a crianças, adolescentes e jovens que primou por desconsiderar os fatores sociais que conjuram as subjetividades. Como lembra Bulcão (2002), as ações da psicologia sempre se voltaram para o atendimento de crianças e adolescentes vivendo nas ruas das grandes cidades, mas esqueceram-se de que elas eram o resultado perverso de mudanças econômicas e políticas: o cenário do fim da escravatura e da imigração europeia na virada para o século XX foram tão ignorados pela psicologia quanto, nas décadas subsequentes, o estreitamento do mercado de trabalho e o crescimento urbano desordenado. Como resultado, os "menores" que vagavam pelas ruas no início do século passado já eram nomeados como perigosos e, como tal, tomados como alvo da tutela, que queria adestrá-los, e do controle, que queria bani-los. Assistimos então, no Brasil, à instalação de um complexo de instituições de sequestro: aquelas que visam fixar indivíduos a aparelhos de normatização, que buscam enquadrar e controlar os sujeitos (FOUCAULT, 1996). Afinal, como lembra Castel (1999, p.138), a razão cínica indica que "quem nada tem para preservar corre o risco de querer apropriar-se de tudo", motivo tido como suficiente para controlar os indivíduos não pela infração efetivamente cometida mas pelo risco de cometê-la: não pelos seus atos, mas pelas suas virtualidades.

No rastro dessa racionalidade, a infância foi alvo das políticas públicas no país através da Roda dos Expostos, do Laboratório de Biologia Infantil, do Serviço de Assistência ao Menor (SAM), da Política Nacional do Bem-Estar do Menor (PNBEM) e dos Códigos de Menores de 1927 e 1979. Nesses espaços, as práticas psicológicas consistiam majoritariamente na elaboração de estudos de caso e laudos que enfocavam a etiologia da infração, as causas da “desagregação familiar" e o desvio produtor da pobreza. Os laudos adotavam o padrão normativo de família, trabalho e moradia forjado no pensamento da elite nacional, de onde deduziam desvios os mais variados: a família que não contasse com a figura paterna era tida como desestruturada, a pobreza era cama de vícios, o "erro" de um colocava toda a família sob suspeição. Em qualquer dessas hipóteses, defendia-se a necessidade de medidas de ressocialização - como se pode facilmente deduzir, aplicadas preferencialmente às crianças e jovens pobres (MARTINS; BRITO, 2003).

Podemos afirmar assim que a inserção da Psicologia nas políticas sociais associou-se a práticas de regulação e controle, estabelecendo padrões de normalidade e anormalidade, circunscrevendo etapas evolutivas e determinando modos de ser e viver. A ação da psicologia sustentou-se (e sustenta-se) em concepções naturalistas do conhecimento, calcadas na objetividade e neutra- 
lidade; esse discurso científico produziu (e ainda produz) subjetividades desqualificadas: o delinquente, o desviante, a família negligente.

Como diz Castel (1999, p.526), a 'nova questão social', "para espanto dos contemporâneos, tem a mesma amplitude e a mesma centralidade da questão suscitada pelo pauperismo na primeira metade do século XIX". Essa semelhança parece induzir a repetição das mesmas estratégias de controle. De fato, mesmo na vigência do Estatuto da Criança e do Adolescente (ECA), algumas práticas psi continuam a fortalecer a crença em modelos hegemônicos, agora com nova roupagem: trocamos o binômio 'criança/menor' por 'criança/criança em situação de risco'; substituímos 'família desestruturada' por 'família vulnerável'; opomos 'população em perigo' - a criança inocente que merece proteção - a 'população perigosa' - aquela da qual a sociedade precisa se proteger.

Foi assim que as políticas públicas nacionais voltadas para a infância tomaram a infância pobre como um importante vetor que aglomerava saberes para manejá-la e controlá-la. Essa lógica repetiu-se nos campos da psicologia, do direito e da educação e atingia uma parcela importante da população, já que no início do século XX a conotação de "infância pobre" incluía os segmentos etários que hoje designamos como adolescentes e jovens (RIZZINI; PILOTTI, 2009).

Nenhum desses segmentos, contudo, pode excluir certa pluralidade, resultado da desigualdade econômica responsável por profundas assimetrias em termos de experiências culturais, sociais e de subjetivação, forjando uma heterogeneidade naquilo que tem sido naturalizado como igual. Abramo e Branco (2005) referem-se especificamente à juventude para sinalizar ali essa assimetria, mas ela se aplica igualmente à infância e à adolescência. Ao destacarmos a diversidade e a multiplicidade dessas experiências de vida no cenário brasileiro, queremos chamar a atenção para estratégias das políticas públicas que, direcionadas aos segmentos mais pobres da população, massificam e equivocadamente tratam cada segmento etário como homogêneo: a criança pobre, o adolescente pobre, o jovem pobre (COIMBRA; NASCIMENTO, 2005; SCISLESKI; REIS; HADLER; WEIGERT; GUARESCHI, 2012). Eles não são homogêneos, e tratá-los como tal é estratégia de uma governamentalidade pautada no controle.

A ideia de governo, tal como adotada aqui, remete àquilo que Foucault (2008b) concebe como biopolítica: a gestão e a administração da população. No sentido proposto pelo autor, o governo não se restringe ao Estado - como usualmente entende o senso comum -, mas indica quaisquer ações e intervenções tomadas para o manejo, a administração e o controle da população, e abarca os diversos agentes sociais que estipulam modos de gerir a população: a mídia, a publicidade, as normativas de saúde, a organização criminosa, 
como também as múltiplas trocas sociais entre os sujeitos, ou seja, a micropolítica. Dizendo de outro modo, as formas de governo dialogam com o campo do poder e, nessa perspectiva, a ideia de governo também deveria implicar - embora nem sempre implique de fato - a possibilidade de negociação por parte da população em relação às ações que lhe são dirigidas.

Por ora, vamos focalizar a análise no campo da Psicologia, embora reconhecendo que esse saber articula-se de perto com o jurídico, o educacional, o psiquiátrico. Não ignoramos, no entanto, que nos deparamos atualmente com um interessante amalgamento jurídico-político: o Estatuto da Criança e do Adolescente (BRASIL, 1990) e o Estatuto da Juventude (BRASIL, 2013) sobrepõem segmentos etários, fazendo com que a população entre 15 e 18 anos seja regida por ambos os diplomas legais; o Estatuto da Criança e do Adolescente preconiza ações que são executadas no âmbito do SUAS, regido por outros diplomas legais; o SUAS, por sua vez, congrega ações voltadas a sujeitos definidos a partir de categorização etária, assim como para instituições sociais, definidas como grupamento: a família. A pergunta que nos colocamos, a partir dessa constatação, indaga o modo como essas estratégias se articulam, e a que propósitos serve essa forma de governamentalidade. Para tanto, vamos tomar como foco algumas situações-índice.

\section{Por que assistência social e qual Psicologia na assistência social?}

\section{a) O Programa Bolsa Família (PBF)}

Um dos objetivos centrais do PBF é levar o usuário a prescindir do auxílio ofertado, razão pela qual o programa não se caracteriza como ação continuada. Segundo as Orientações Técnicas sobre o Serviço de Proteção e Atendimento Integral à Família (BRASIL, 2012, p.13), o psicólogo deve "provocar impactos na dimensão da subjetividade dos usuários, tendo como diretriz central a construção do protagonismo e da autonomia, na garantia dos direitos com superação das condições de vulnerabilidade social e potencialidades de riscos." Como se vê, o documento anuncia que o usuário é o responsável pela própria vulnerabilidade e, mediante esforço individual, pode superar a pobreza. Nesse arranjo, o psicólogo ora culpabiliza o usuário - quando não consegue alcançar autonomia -, ora a si próprio - quando sua ação não logra retirá-lo da pobreza.

O capitalismo nacional faz da política social uma política necessariamente compensatória. "Uma política social que tivesse por objeto principal a igualização, ainda que relativa, que adotasse como tema central a repartição, ainda que relativa, essa política social seria necessariamente antieconômica" (FOUCAULT, 2008a, p.196). 
A transferência de renda propiciada pelo PBF apenas garante condições mínimas de gerir os riscos, mantendo-os em patamares suportáveis. São quase 14 milhões de famílias cadastradas, motivo pelo qual as mulheres associam a assistência social ao bolsa família, tomando-os quase como sinônimos, e complementam: "é pouco, mas ajuda". Os usuários do PBF são incluídos no Cadastro Único dos Programas Sociais (CadÚnico) ${ }^{2}$ e monitorados quanto ao cumprimento das condicionalidades: manter os filhos na escola, garantir cuidados básicos em saúde (p.ex. vacinação das crianças entre 0 e 6 anos), cumprir a agenda pré e pós-natal para mulheres. Qualquer descumprimento aciona a busca ativa ${ }^{3}$, atividade sob responsabilidade dos técnicos sociais (psicólogo, assistente social, educador social) do CRAS. O cadastramento das famílias torna possível gerenciar a miséria, donde afirmamos que o CadÚnico pode ser lido como dispositivo de controle e vigilância: esse conjunto heterogêneo que engloba práticas e enunciados científicos, morais e filantrópicos, e que ancora jogos estratégicos de poder (FOUCAULT, 1989). Se os técnicos sociais não dão conta da demanda, multipliquem-se os equipamentos de controle: em Porto Alegre, o Serviço de Atenção à Família (SAF) foi criado como braço auxiliar do CRAS na identificação e acompanhamento das famílias que não atendem às condicionalidades.

Então, por que a Psicologia na assistência? O que é demandado ao psicólogo? Não parece possível escapar das demandas específicas da assistência. A inclusão no trabalho é um imperativo e os efeitos do SUAS na empregabilidade dos psicólogos é expressiva: segundo dados do Censo SUAS (2015), mais de 15 mil psicólogos trabalham hoje nas unidades públicas estatais e de

\footnotetext{
Informações retiradas do diário de campo da pesquisa "Entre as práticas psicológicas e a Política Pública de Assistência Social: um estudo a partir do PAIF em Porto Alegre". Uma produção de dados parcial foi publicada em: SANTOS, N. L.; ROESCH, D.; CRUZ, L. R. da. Vulnerabilidade e risco social: produção de sentidos no campo socioassistencial. Revista Jovens Pesquisadores, v. 4, p. 119-127, 2014.

2 O CadÚnico é considerado a porta de entrada do CRAS, "pois é através dele que as famílias passam a existir para a Política. Trata-se de um instrumento (preenchimento digital) cujo objetivo é registrar informações que permitam a identificação do domicílio e da família através de questões estruturadas e distribuídas em 10 blocos distintos: 1) identificação e controle; 2) características do domicílio; 3) família; 4) identificação da pessoa; 5) documentos; 6) pessoas com deficiência; 7) escolaridade; 8) trabalho e remuneração; 9) responsável pela unidade familiar (RF); 10) marcação livre para o município. Nesse procedimento, chama atenção o detalhamento das condições de vida, do modo de viver que o formulário requisita para os sujeitos que desejam cadastrar-se no serviço" (RODRIGUES; GUARESCHI; CRUZ, 2013, p.15).

3 A busca ativa é definida como a "procura intencional, realizada pela equipe de referência do CRAS, das ocorrências que influenciam o modo de vida da população em determinado território", tendo por "objetivo identificar as situações de vulnerabilidade e risco social, ampliar o conhecimento e a compreensão da realidade social, para além dos estudos e estatísticas", contribuindo para "o conhecimento da dinâmica do cotidiano das populações; os apoios e recursos existentes e seus vínculos sociais" (BRASIL, 2009, p. 29). A busca ativa encontra seu apoio em uma característica dos programas da Assistência Social: as condicionalidades.
} 
gestão. Para eles, não é impossível inventar práticas que operem para além dos dispositivos de normalização das condutas dos indivíduos e famílias. Apostamos no campo socioassistencial como fértil produtor de agenciamentos, onde os movimentos de resistência se atualizam nas práticas cotidianas. Como ensina Foucault, não devemos "nunca nos limitar a fazer o que nos resta fazer" (1994, apud SOALHEIRO e AMARANTE, 2008, p. 131). O exercício da crítica é fundamental e precisa ser utilizado em processos conflituosos, de afrontamentos, de tentativas e de recuos.

\section{b) Políticas sociais e segurança pública}

Como escreveu Deleuze (2000, p. 224), “o capitalismo manteve como constante a extrema miséria de três quartos da humanidade, pobres demais para a dívida, numerosos demais para o confinamento: o controle não só terá que enfrentar a dissipação das fronteiras, mas também a explosão dos guetos e favelas". O alerta parece especialmente significativo quando a atenção aos adolescentes que cumprem medida socioeducativa (MSE) adentra o espaço da assistência social, aproximando aquilo que é mais propriamente assistência de mecanismos historicamente destinados ao controle. Adolescentes ditos "em perigo" frequentam os mesmos espaços daqueles ditos "perigosos", eles e seus familiares assistidos pelas mesmas equipes nos mesmos equipamentos sociais, sob as mesmas diretrizes.

Com efeito, a Resolução CNAS 18/2014 dispõe que o co-financiamento federal, estadual e municipal tem por objetivo prover atendimento e acompanhamento socioassistencial a adolescentes que cumprem medida em meio aberto, a Liberdade Assistida e a Prestação de Serviços à Comunidade, promovendo acesso a direitos e buscando a ressignificação de valores pessoais e sociais desses jovens. No art. $4^{\circ}$, a Resolução enumera os serviços complementares, que devem concorrer para esses objetivos: o Serviço de Convivência e Fortalecimento de Vínculos (SCFV), que deve reforçar o convívio familiar, comunitário e social, e a autonomia individual, familiar e social; o Serviço de Proteção e Atendimento Especializado às Famílias e Indivíduos (PAEFI) e o Serviço de Proteção e Atendimento Integral à Família (PAIF), ambos voltados para o acompanhamento às famílias, o segundo voltado especificamente para o fortalecimento de seu papel protetivo em contexto de vulnerabilidade e risco pessoal e social; e o Programa Nacional de Promoção do Acesso ao Mundo do Trabalho (Acessuas-Trabalho), que acompanha o adolescente a partir de 14 anos (como aprendiz) ou a partir de 16 anos (para sua profissionalização).

As MSE englobam a advertência; a obrigação de reparar o dano; a prestação de serviços à comunidade (PSC); a liberdade assistida (LA); a inserção 
em regime de semi-liberdade; e a internação (BRASIL, 1990, art. 112). A PSC e a LA tanto podem ser aplicadas ao adolescente que recebe pela primeira vez uma medida judicial quanto ao adolescente que, tendo sido alvo de medida restritiva ou privativa de liberdade, conquista o direito de cumpri-la em meio aberto. Caracteriza-se, assim, o trânsito do adolescente entre os diversos equipamentos do sistema socioeducativo, e agora - com o ingresso do CREAS no rol de equipamentos voltados para a socioeducação - também dos equipamentos da assistência social.

O Estatuto quis, com reformas significativas no trato da adolescência em conflito com a lei, destituir o lugar da mera punição e valorizar a perspectiva educativa, e de responsabilização. Não é à toa que, alinhadas às medidas socioeducativas, a lei coloca a possibilidade de aplicação cumulativa, pelo Juiz, de medidas protetivas. O entendimento que subjaz ao art. 112 é que o cometimento de ato infracional pelo adolescente deve ser entendido sobretudo como um acidente, correlato da desatenção para com seus direitos. Traduziase assim uma lógica de comprometimento amplo, da família, da sociedade e do Estado, no trato da infância e da adolescência.

Tempos de sanha punitiva - mais apropriados ao neoliberalismo - puseram por terra essa proposição. Como demonstrou Wacquant (2001) com veemência, a retração das políticas públicas, a mobilização do medo e a construção da crença de que segurança social se faz a partir de segurança policial, enfraqueceram os argumentos em prol de uma segurança edificada com fundamento na cidadania, não no controle. Em tempos neoliberais, é preciso lutar pelos postos no mercado de trabalho (não importa se mal remunerados ou precários), ou expor-se ao controle penal. O perigo assombra a todos, e os perigosos serão buscados através de todas as fronteiras.

A fronteira entre a assistência e o controle, tênue pelas razões que já expusemos neste texto, convivem agora com um novo risco: irão os psicólogos, integrantes das equipes do CREAS, fazer prevalecer uma ou outra?

Rezam nossos mais caros princípios jurídicos que a pena (e tomamos aqui, neste particular, a MSE como seu correlato) não deve atingir ninguém além do autor do delito. No espaço socioeducativo da internação, a família do adolescente parece desconhecer esse princípio. Ali, ela é convocada como coadjuvante de um processo que desconhece, é convidada a circular em instituições cuja lógica lhe é estranha, e cobrada a atuar sem que lhe sejam ofertados recursos mínimos, mesmo quando eles são imprescindíveis a sua efetiva participação (GONÇALVES, 2011).

Nas políticas de assistência, são as famílias mais uma vez convocadas a comparecer como parceiras, nomeadas em todos os programas que sustentam 
a ação do CREAS na socioeducação. Resta nos indagarmos qual lógica lhes será destinada: elas serão instrumentos de controle ou alavanca de cidadania?

\section{c) O que a Psicologia faz com o sujeito jovem?}

Quando pensamos as políticas públicas voltadas para essa categoria da população, com frequência encontramos práticas de gestão relativas a uma faixa etária e a uma situação econômica particular (SCISLESKI et al, 2012; RIZZINI; PILOTTI, 2009).

Como nossa discussão visa debater as práticas psi voltadas à população juvenil e pobre, não vamos nos delongar na questão jurídico-política, apesar dela trazer algumas intercorrências interessantes. Cabe destacar, no entanto, que diversos pesquisadores (COIMBRA; NASCIMENTO, 2005; SCISLESKI; GALEANO; SILVA; SANTOS; 2014; FAUSTINO; HÜNING, 2015; BICALHO; BARBOZA; MEZZA, 2015; RIZZINI; PILOTTI, 2009; VICENTIN, 2005) têm apontado que a atuação da Psicologia junto à juventude pobre tem-se pautado por aquilo que poderíamos designar como uma certa descartabilidade dessa população. Alguns indícios disso seriam uma administração feita a partir de critérios classificatórios: juventude perigosa, juventude em perigo, juventude assistida e juventude delinquente são rótulos discriminatórios que segmentam com base na falta e no desvio, pouco acrescentando à compreensão da juventude. Ao mesmo tempo, outros estudos, como o Mapa da Violência (WAISELFISZ, 2013), indicam que nessa mesma faixa etária alguns segmentos são particularmente vulneráveis, expostos a ações cotidianas de extermínio.

Nas pesquisas mencionadas, encontramos que as práticas psicológicas têm, de modo geral, produzido a estigmatização da juventude pobre, a partir de laudos, relatos de entrevistas, pareceres, etc. Isso nos leva a questionar em primeiro plano a postura do profissional - que não necessariamente adota essa posição por desinteresse ou má fé, mas por desconhecimento e pelo excesso de funções e demandas, impeditivos de uma reflexão mais consistente sobre os efeitos que suas ações acarretam. Não se trata aqui de culpabilizar o psicólogo, mas de colher elementos que permitam pensar sua formação, sobretudo levando em conta que os currículos de Psicologia pouco abordam questões sociais, trabalhando majoritariamente a perspectiva individual, como o fazem vários segmentos da clínica e da avaliação psicológica (GUARESCHI; REIS; DHEIN; BENNEMANN; MARCHY, 2011; MACEDO; DIMENSTEIN, 2013).

A maioria das práticas psicológicas dirigidas à juventude pobre produz patologização e estigmatização dos sujeitos, a partir de pareceres e laudos que se dedicam a abordá-los em sua dimensão estritamente individual, como se 
vivessem e se constituíssem descolados do contexto social; outros laudos e pareceres, quando querem contextualizar o sujeito, remetem a vagas definições de "famílias desestruturadas" (LOBO; COIMBRA; NASCIMENTO, 2012), naturalizando os destinos desses jovens, colando-os, por exemplo, à criminalidade. A associação perversa entre criminalidade e pobreza, por exemplo, persiste como produto da naturalização que seleciona a ação, e pressupõe a intenção, condizentes com o delito.

\section{Dê-me um possível...}

É na vigência do ECA e, principalmente, após o SUAS que a Psicologia se insere definitivamente no campo denominado políticas públicas de assistência social. O debate é recente e, diante do desconhecido, Bernardes e Hillesheim (2012, p.378) mostram que há o risco da psicologia repetir velhas práticas, mas há também aí uma janela de invenção.

É fundamental não perdermos de vista que a Psicologia pode (e deve) apostar na potência de vida. Na contramão de discursos que essencializam e naturalizam destinos, a aposta na potência de vida implica em trabalhar com ferramentas contrárias à estigmatização: o que podemos fazer para não patologizar sujeitos, para não correlacionar violência, crime e pobreza, para inaugurar possibilidades outras de vida que não cumpliciem com teorias deterministas que dissimulam fascismos?

Diante de situações tão tristemente frequentes entre adolescentes e jovens pobres - exposição e aliciamento do crime organizado, estigmatização e preconceito social - e diante dos dramas múltiplos que submetem as famílias renda insuficiente, amparo deficitário em educação e saúde - é indispensável pensarmos possibilidades de abertura, criação e invenção de outras práticas. É mister pensar em linhas que fujam (DELEUZE; GUATTARI, 1996) do encapsulamento em diagnósticos, pareceres ou quaisquer outras estratégias que restrinjam o sujeito e resumam sua vida ao fracasso na perspectiva neoliberal. Tais linhas de fuga buscam dar vazão e escape a processos mortificadores que capturam jovens pobres. Nesse sentido, cabe à Psicologia abrir saídas, colocar em questão e problematizar práticas de "redução" no intuito de ampliar as possibilidades de vida, de tocá-las a partir de afetos e afetações que - mais do que potencializar um futuro aos jovens - proporcione a eles condições de habitar um presente vasto.

A práxis do psicólogo vai sendo constituída em uma proliferação de discursos: são práticas que se traduzem em novas políticas públicas, e saberes que edificam novos parâmetros de atuação profissional, produzindo novos sentidos, estabelecendo novas relações. Ao discutir os modos como os dis- 
cursos científicos constituem-se em regimes de verdade que formam sujeitos, Foucault questiona as possibilidades e limitações da Ciência psicológica e propõe pensar que outras formas eles podem assumir, problematizando os objetivos a que se vinculam e os modos de subjetivação que produzem. Se levarmos em consideração que as Políticas Públicas são dispositivos de subjetivação, não se pode ignorar que numa governamentalidade neoliberal, como é o caso do Brasil, seu foco é a ação que orienta, assiste e vigia as populações pobres. O pensamento foucaultiano permite desnaturalizar práticas institucionalizadas e problematiza as implicações das formas de governo do indivíduo e dos coletivos; a busca da regulação, da normalização, da adaptação e do controle; a produção do equilíbrio social por meio das práticas psicológicas na assistência social e na segurança; e as políticas de juventude e família em seus laços com a 'pobreza psíquica' e o 'risco social' que 'desorganiza' o tecido social, gerando a necessidade de governo e, por vezes, de tutela. Esse arranjo reorganiza as práticas psicológicas e as aproxima do campo do Direito e da cidadania, onde se torna imperioso a permanente problematização de pelo menos três questões: o que estamos fazendo; como estamos fazendo e quais os efeitos dessas práticas.

\section{Referências}

ABRAMO, H. W.; BRANCO, P. P. M. Retratos da juventude brasileira: análises de uma pesquisa nacional. São Paulo: Fundação Perseu Abramo, 2005.

BICALHO, P. P.; BARBOZA, R., B.; MEZZA, A. P. S. Juventude no fogo cruzado: o governo da vida e as políticas dicotômicas de segurança. In SCISLESKI, A.; GUARESCHI, N. (Org.). Juventude, marginalidade e direitos humanos: da psicologia às políticas públicas. Porto Alegre: Edipucrs, 2015, p. 205-220.

BRASIL. Orientações Técnicas sobre o Serviço de Proteção e Atendimento Integral à Família $(P A I F)$. Ministério do Desenvolvimento Social e Combate à Fome. Secretaria Nacional de Assistência Social. Brasília: MDS, 2012.

BRASIL. Estatuto da juventude. Lei Federal 12852. Brasília: 2013.

BRASIL. Orientações Técnicas: Centro de Referência da Assistência Social (CRAS). Ministério do Desenvolvimento Social e Combate à Fome. Secretaria Nacional de Assistência Social. Brasília: MDS, 2009.

BRASIL. Política Nacional de Assistência Social. Ministério do Desenvolvimento Social e Combate à Fome - Secretaria Nacional de Assistência Social, 2004.

BRASIL. Estatuto da criança e do adolescente. Lei Federal 8069. Brasília: 1990.

BRASIL. Constituição. Constituição da República Federativa do Brasil. Brasília/DF: Senado, 1988. 
BERNARDES, A.; HILLESHEIM, B. Insistência em minorar: reflexões sobre políticas públicas e saúde. Avances en Psicología Latinoamericana, v.30, n. 2, p. 369-380, 2012.

BULCÃO, I. A produção de infâncias desiguais: uma viagem na gênese dos conceitos 'criança' e 'menor'. In: NASCIMENTO, M. L. (Org.). Pivetes: a produção de infâncias desiguais. Niterói: Intertexto; Rio de Janeiro: Oficina do Autor, 2002, p. 61-73.

CASTEL, R. Metamorfoses da questão social: uma crônica do salário. Petrópolis: Vozes, 1999.

LOBO, L.; COIMBRA, C.; NASCIMENTO, M. L. Anotações iniciais sobre a psiquiatria do desenvolvimento ou 'é de pequeno que se torce o pepino'. Psicologia Política, n.12, p. 87-103, 2012 .

COIMBRA, C.; NASCIMENTO, M. L. Ser jovem, ser pobre é ser perigoso? Imagens sobre a juventude. Jovenes, Revista de Estudios sobre Juventud, México, n.9, v.22, p. 338-355, 2005.

DELEUZE, G. Conversações. Rio de Janeiro: Ed. 34, 2000.

DELEUZE, G.; GUATTARI, F. Mil platôs: capitalismo e esquizofrenia, vol. 3. Rio de Janeiro: Editora 34, 1996.

FAUSTINO, G.; HÜNING, S. M. O plano "Juventude Viva” em Alagoas e a naturalização da relação entre juventude e violência. In SCISLESKI, A.; GUARESCHI, N. (Org.). Juventude, marginalidade e direitos humanos: da psicologia às políticas públicas. Porto Alegre: Edipucrs, 2015, p. 95-108.

FOUCAULT, M. Nascimento da biopolítica. São Paulo: Martins Fontes, 2008a.

FOUCAULT, M. Segurança, território, população. São Paulo: Martins Fontes, 2008b.

FOUCAULT, M. A verdade e as formas jurídicas. 10.ed. Rio de Janeiro: NAU, 1996.

FOUCAULT, M. Sobre a História da Sexualidade. In: FOUCAULT, M. Microfísica do Poder. Rio de Janeiro: Graal, 1989, p. 243-276.

GONÇALVES, H. S. Sobre a participação da família no processo socioeducativo. In: DAYRELL, J.; MOREIRA, M. I. C.; STENGEL, M. (Org..) Juventudes contemporâneas: um mosaico de possibilidades. Belo Horizonte: Ed. PUC Minas, 2011, p. 379-397.

GUARESCHI, N.; REIS, C. dos; DHEIN, G.; BENNEMANN, T.; MARCHY, D. A avaliação psicológica, psicopatologia e psicoterapias na formação do profissional de saúde para o SUS: um estudo dos currículos dos cursos de Psicologia. Revista Mal-estar e subjetividade, n.1, p. 171-204, 2011.

MACEDO, J. P.; DIMENSTEIN, M. D. Ação política-profissional dos psicólogos e a Reforma Psiquiátrica. Estudos de Psicologia (Natal), 18, p.297-304, 2013.

MARTINS, C. da F.; BRITO, L. M. T. A inserção do psicólogo no sistema de atendimento ao adolescente em conflito com a lei no Brasil. In: JACÓ-VILELA, A. M.; CEREZZO, A. C.; RODRIGUES, H. B. C. (Org.). Clio-Psyché paradigmas: historiografia, psicologia, subjetividades. Rio de Janeiro: Relume Dumará/FAPERJ, 2003, p. 371-377. 
OLIVEIRA, L. de A. O laboratório de biologia infantil: discurso científico e assistência no Juizado de menores. In: JACÓ-VILELA, A. M.; CEREZZO, A. C.; RODRIGUES, H. B. C. (Org.). Clio-Psyché ontem: fazeres e dizeres psi na história do Brasil. Rio de Janeiro: Relume Dumará/FAPERJ, 2001, p. 237-242.

RIZZINI, I.; PILOTTI, F. A arte de governar crianças: a história das políticas sociais, da legislação e da assistência à infância no Brasil. São Paulo: Cortez, 2009.

RODRIGUES, L.; GUARESCHI, N. M. de F.; CRUZ, L. R. da. A centralidade do vínculo familiar e comunitário nas políticas públicas de assistência social. In: RODRIGUES, L.; GUARESCHI, N. M. F.; CRUZ, L. R. da (Org.). Interlocuções entre a Psicologia e a Política Nacional de Assistência Social. Santa Cruz do Sul: EDUNISC, 2013, p. 11-22.

SCISLESKI, A.; GALEANO, G.; SILVA, J. L. C.; SANTOS, S. S. Medida socioeducativa de internação: dos corpos dóceis às vidas nuas. Psicologia: Ciência e Profissão, n.34, v.3, p. 660$675,2014$.

SCISLESKI, A.; REIS, C. dos; HADLER; O.; WEIGERT, M. A. B.; GUARESCHI, N. Juventude e pobreza: a construção de sujeitos potencialmente perigosos. Arquivos Brasileiros de Psicologia, Rio de Janeiro, n. 64, v.3, p. 19-34, 2012.

SOALHEIRO, N. I.; AMARANTE, P. D. Reflexões em torno da temática da política e das reformas no campo da psiquiatria, a partir de Michel Foucault e do Movimento dos usuários dos serviços de saúde mental. In: PASSOS, I. C. F. (Org.). Poder, normalização e violência: incursões foucaultianas para a atualidade. Belo Horizonte: Autêntica, 2008, p. 127-140.

VICENTIN, M. C. G. A vida em rebelião: jovens em conflito com a lei. São Paulo: Hucitec, 2005.

WACQUANT, L. As Prisões da Miséria. Rio de Janeiro: Zahar, 2001.

WAISELFISZ, J. Mapa da Violência: homicídios e juventude no Brasil. Rio de Janeiro: Flacso, 2013 .

Submissão em: 25/02/2015

Revisão em: 14/07/2015

Aceite em: 16/08/2015

Andréa Cristina Coelho Scisleski é psicóloga; doutora em Psicologia pela Pontifícia Universidade Católica do Rio Grande do Sul (PUC-RS). Docente do Programa de Pós-graduação em Psicologia da Universidade Católica Dom Bosco (UCDB). E-mail: ascisleski@yahoo.com.br

Hebe Signorini Gonçalves é psicóloga; doutora em Psicologia pela Pontifícia Universidade Católica do Rio de Janeiro (PUC-RJ). Docente do Programa de Pós-graduação em Psicologia da Universidade Federal do Rio de Janeiro (UFRJ).

E-mail: hebe@globo.com 
Lilian Rodrigues da Cruz é psicóloga; pós-doutora em Psicologia Social e Institucional pela Universidade Federal do Rio Grande do Sul (UFRGS); doutora em Psicologia pela Pontifícia Universidade Católica do Rio Grande do Sul (PUCRS). Docente do Instituto de Psicologia - Departamento de Psicologia Social e Institucional - e do Programa de Pós-Graduação em Psicologia Social e Institucional da Universidade Federal do Rio Grande do Sul (UFRGS). E-mail: liliancruz2@terra.com.br 